Methods: FUTURE 5 is a randomised, double-blind, placebo-controlled 2-year phase 3 trial in pts with active PsA. ${ }^{2}$ Pts randomised to SEC $150 \mathrm{mg}$ could be escalated to $300 \mathrm{mg}$ from Week (Wk) 52 to 104, based on investigators' judgement. The pts were categorised as either not achieving REM/LDA, achieving it once only or sustained REM/LDA, which was defined as pts who achieved REM/ LDA between Wks 24-52 and maintained the same response at least 2 of the next 6 visits (visit every 8 Wks). Of pts who did not achieve REM/LDA, achieved REM/LDA (VLDA, DAPSA REM, MDA, DAPSA LDA+REM) between Wk 24 and 52 , the relationship between absence of REM/LDA, REM/LDA, sustained REM/ LDA, proportion of pts with non-radiographic progression (assessed using the van der Heijde [mTSS]), physical function (health assessment questionnaire disability index [HAQ-DI]), and short form-36 physical component score [SF-36 PCS] $)^{3}$ were assessed.

Results: In total, 996 pts were randomised to one of 4 treatment groups: SEC $300 \mathrm{mg}$ loading dose (LD; $\mathrm{N}=222)$, SEC $150 \mathrm{mg}$ LD ( $\mathrm{N}=220)$, SEC $150 \mathrm{mg}$ no loading dose ( $\mathrm{NL} ; \mathrm{N}=222)$, and placebo $(\mathrm{N}=332)$. The baseline clinical characteristics were comparable across treatment groups. Majority of pts could achieve either sustained MDA/sustained DAPSA LDA+REM (Figure 1). Pts achieving REM/LDA, whether at one visit or consistently, showed improved physical function and SF36-PCS at Wk $104 .{ }^{3} \mathrm{~A}$ high proportion of pts did not show radiographic progression at Wk 104 irrespective of achievement of REM/LDA category (Table 1).

Conclusion: The majority of patients treated with secukinumab were able to achieve sustained LDA. Sustained LDA/REM was associated with improved HRQoL, physical function and inhibition of structural damage progression. REFERENCES:

[1] Coates LC, et al. J Rheumatol. 2018;46(1):38-42.

[2] Van der Heijde D, et al. Rheumatology. 2020;59(6):1325-1334.

[3] Coates L, et al. [0353]. Arthritis Rheumatol. 2020;72 (suppl 10).

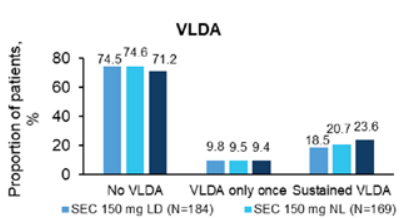

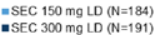
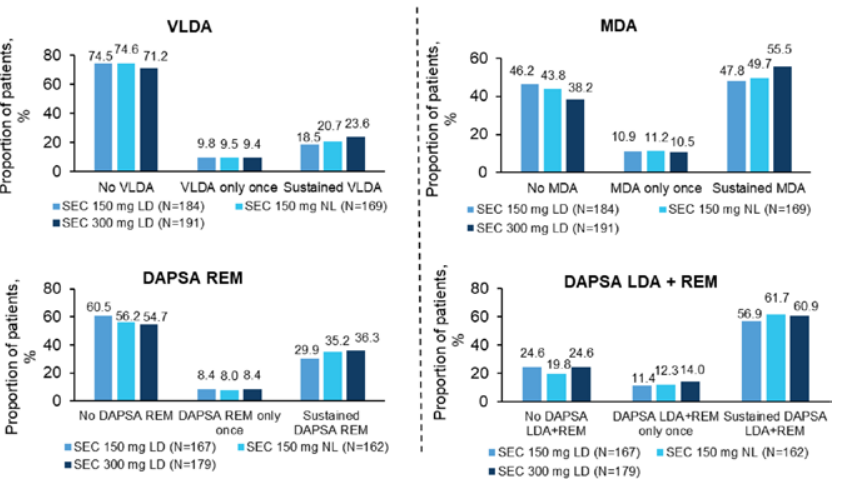

Figure 1. Proportion of patients achieving VLDA/MDA/DAPSA REM/DAPSA REM+LDASustained REM/LDA was defined if the same response was achieved at least 2 out of the next 6 visits (every 8 weeks), respectively. DAPSA, Disease activity in Psoriatic Arthritis; LD, loading dose; LDA, Low Disease Activity; MDA, Minimal Disease Activity; N, number of randomised patients assessed at both Week 24 and 104; NL, without loading dose; REM, remission; SEC, secukinumab; VLDA, Very Low Disease Activity

Table 1. Percentage of vdH-mTSS no progression at Week 104 (change from baseline $\leq 0.5$ ) by REM/LDA and sustained REM/LDA status

\begin{tabular}{|c|c|c|c|c|}
\hline $\begin{array}{l}\text { REM and LDA composite indices, } \\
\text { n (\%) }\end{array}$ & Treatment group & $\begin{array}{l}\text { p No REM/ } \\
\text { LDA }\end{array}$ & $\begin{array}{l}\text { REM/LDA } \\
\text { only once }\end{array}$ & $\begin{array}{l}\text { Sustained } \\
\text { REM/LDA }\end{array}$ \\
\hline \multirow[t]{3}{*}{ MDA } & SEC $150 \mathrm{mg}$ LD & 64 (75.3) & $16(80.0)$ & $76(86.4)$ \\
\hline & SEC $150 \mathrm{mg} \mathrm{NL}$ & $56(75.7)$ & 15 (78.9) & $69(82.1)$ \\
\hline & SEC $300 \mathrm{mg}$ LD & $58(79.5)$ & $19(95.0)$ & $100(94.3)$ \\
\hline \multirow[t]{3}{*}{ VLDA } & SEC $150 \mathrm{mg}$ LD & $108(78.8)$ & 15 (83.3) & 30 (88.2) \\
\hline & SEC $150 \mathrm{mg} \mathrm{NL}$ & 95 (75.4) & $13(81.3)$ & 32 (91.4) \\
\hline & SEC $300 \mathrm{mg}$ LD & $115(84.6)$ & 17 (94.4) & $45(100.0)$ \\
\hline \multirow[t]{3}{*}{ DAPSA REM } & SEC $150 \mathrm{mg}$ LD & 77 (76.2) & 11 (78.6) & 46 (92.0) \\
\hline & SEC $150 \mathrm{mg} \mathrm{NL}$ & 65 (71.4) & $10(76.9)$ & $50(87.7)$ \\
\hline & SEC $300 \mathrm{mg}$ LD & $82(83.7)$ & 14 (93.3) & 63 (96.9) \\
\hline \multirow[t]{3}{*}{ DAPSA LDA + REM } & SEC $150 \mathrm{mg}$ LD & $29(70.7)$ & $16(84.2)$ & $80(84.2)$ \\
\hline & SEC $150 \mathrm{mg} \mathrm{NL}$ & $23(71.9)$ & $15(75.0)$ & $79(79.0)$ \\
\hline & SEC $300 \mathrm{mg}$ LD & $39(88.6)$ & $21(84.0)$ & $97(89.0)$ \\
\hline
\end{tabular}

Sustained REM/LDA was defined if the same response was achieved at least twice out of the next 6 visits (every 8 weeks), respectively. n, number of evaluable patients; vdH-mTSS, van der Heijde- modified total Sharp score

Disclosure of Interests: Laura C Coates Consultant of: Abbvie, Amgen, Biogen, Boehringer Ingelheim, Celgene, Galapagos, Gilead, Janssen, Lilly, Novartis, Pfizer and UCB, Grant/research support from: Abbvie, Celgene, Lilly, Novartis and Pfizer, Philip J Mease Speakers bureau: AbbVie, Amgen, Janssen, Lilly,
Novartis, Pfizer and UCB, Consultant of: AbbVie, Amgen, BMS, Boehringer Ingelheim, Galapagos, Celgene, Genentech, Gilead, Janssen, Lilly, Novartis, Pfizer, SUN Pharma, and UCB, Grant/research support from: AbbVie, Amgen, BMS, Celgene, Galapagos, Gilead, Janssen, Lilly, Novartis, Pfizer, SUN, and UCB, Dafna D Gladman Consultant of: Abbvie, Amgen, BMS, Celgene, Eli Lilly, Gilead, Galapagos, Janssen, Novartis, Pfizer and UCB, Grant/research support from: Abbvie, Amgen, BMS, Celgene, Eli Lilly, Gilead, Galapagos, Janssen, Novartis, Pfizer and UCB, Sandra Navarra Speakers bureau: Pfizer, Novartis, Astra-Zeneca, Janssen, Lilly, and Astellas, Consultant of: Pfizer, Novartis, Astra-Zeneca, Janssen, Lilly, and Astellas, Weibin Bao Shareholder of: Novartis, Employee of: Novartis, Corine Gaillez Shareholder of: Novartis and BMS, Employee of: Novartis.

DOI: 10.1136/annrheumdis-2021-eular.1971

\section{POS1052 PSORIATIC ARTHRITIS AND OBESITY IMPACT DRUG PERSISTENCE IN USTEKINUMAB-TREATED PATIENTS WITH PSORIASIS IN THE BRITISH ASSOCIATION OF DERMATOLOGISTS BIOLOGIC AND IMMUNOMODULATORS REGISTER (BADBIR): A 10-YEAR FOLLOW-UP STUDY}

A. Ogdie ${ }^{1}$, W. Tillett ${ }^{2}$, A. Passey ${ }^{3}$, P. Gorecki ${ }^{4} .{ }^{1}$ University of Pennsylvania, Perelman School of Medicine, Philadelphia, United States of America; ${ }^{2}$ Royal National Hospital for Rheumatic Diseases, Rheumatology, Bath, United Kingdom; ${ }^{3}$ Janssen Real World Evidence, HEMAR EMEA, High Wycombe, United Kingdom; ${ }^{4}$ Janssen, Medical Affairs, High Wycombe, United Kingdom

Background: Up to $80 \%$ of patients with psoriatic arthritis (PsA) have comorbid psoriasis (PsO). ${ }^{1}$ However, data on the impact of comorbid PsA on treatment persistence in PsO patients are limited with mixed findings. ${ }^{2-4}$ Other factors have been implicated in predicting response to treatment, including obesity, which is associated with PsA and has demonstrated a varying effect on biologic persistence..$^{2,3,5,6}$

Objectives: The primary objective of this study was to evaluate whether comorbid PsA and obesity impact ustekinumab (UST) persistence in PsO patients using the British Association of Dermatologists Biologic and Immunomodulators Register (BADBIR). Additionally, the effect of line of therapy was investigated. Methods: This retrospective observational study used data from PsO patients receiving UST in the BADBIR (first enrolled 07/2009; 10/2020 data cut-off). Time to discontinuation (TTD) was defined as time from treatment start date until treatment stop date, censoring for loss to follow-up where patients are lost to follow-up or active in the registry without a recorded treatment stop date. KaplanMeier survival analysis was used to estimate probability of discontinuation over time and median TTD. Patients were stratified by PsA diagnosis (recorded as a comorbidity at enrolment) and prior biologic experience (history of treatment with $\geq 1$ other biologic). The log-rank test was used to compare persistence among groups. Hazard ratios (HRs), confidence intervals $(\mathrm{Cl})$ and $p$-values for effect of obesity, PsA status and prior biologic exposure on TTD were generated using Cox proportional hazards regression.

Results: Univariate analysis found that median TTD was shorter for patients with comorbid PsO and PsA (5.04 years; $n=585$ ) vs. patients with PsO alone (7.19 years; $n=2698 ; p<0.0001$ ). Biologic-experienced patients with comorbid $\mathrm{PsO}$ and PsA $(\mathrm{n}=292)$ had a significantly higher likelihood of discontinuation than any other group, with a median TTD of 3.84 years $(p<0.0001$; Figure 1). In

Fig. 1: Drug survival in patients with $\mathrm{PsO}$ treated with UST, stratified by presence of comorbid PsA and prior biologic experience.

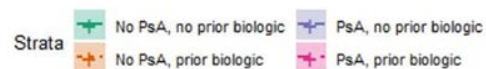
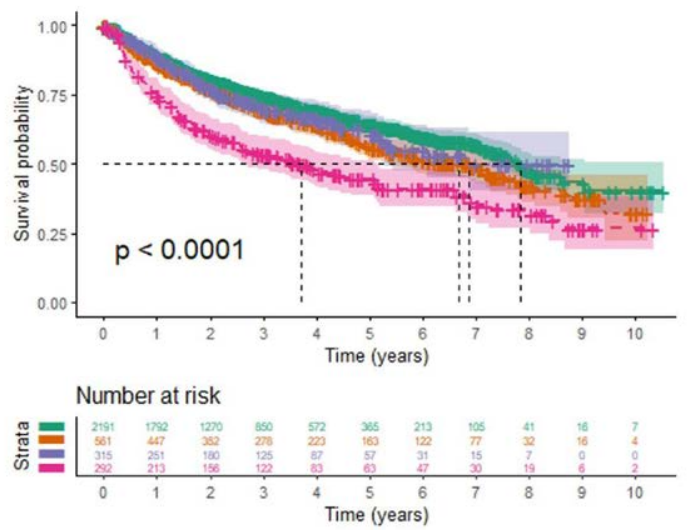

p-value for drug survival probability across all groups. PsA, psoriatic arthritis; PsO, psoriasis; UST, ustekinumab. 
multivariable models, biologic-experienced patients were more likely to discontinue treatment (HR 1.21 [95\% Cl 1.04-1.43]; $p=0.017$ ) vs. biologic-naïve patients, while PsA had no significant effect on TTD alone vs. no PsA (HR 1.12 [95\% Cl 0.9-1.4]; $p=0.31$ ). However, comorbid PsA increased the likelihood of treatment discontinuation for biologic-experienced patients (HR 1.45 [95\% Cl 1.06-1.97]; $\mathrm{p}=0.018$ ). Obesity was a further predictor of discontinuation (HR $1.15[95 \% \mathrm{Cl}$ $1.02-1.31] ; p=0.027$ ) and this was independent of comorbid PsA and prior biologic exposure (Table 1).

Conclusion: Comorbid PSA was associated with reduced time-to-discontinuation of UST in biologic-experienced patients, but not biologic-naïve patients. Obesity also impacted TTD but independently of PsA status.

\section{REFERENCES :}

[1] Coates and Helliwell. Clin Med 2017;17:65-70

[2] Menter et al. J Eur Acad Dermatol Venereol 2016;30:1148-58

[3] Mourad et al. Br J Dermatol 2019;181:450-8

[4] Yiu et al. Br J Dermatol 2020;183:294-302

[5] Mease et al. RMD Open 2015;1:e000181

[6] Costa et al. Clin Rheumatol 2019;38:2355-62

Table 1. Multivariate analysis of UST discontinuation in PsO patients $(\mathrm{N}=3,174)$.

\begin{tabular}{lllll}
\hline Covariate & Status $(n)$ & HR & $95 \%$ Cl & p-value \\
\hline Comorbid PsA & No PsA & ref & - & - \\
& $(n=2609)$ & & & \\
& PsA & 1.12 & $0.90-1.40$ & 0.31 \\
& $(n=565)$ & & & \\
Biologic experience & No prior biologic $(n=2371)$ & ref & - & - \\
PsA*prior biologic experience & Prior biologic $(n=803)$ & 1.21 & $1.04-1.43$ & 0.017 \\
& No PsA, prior biologic & ref & - & - \\
& $(n=539)$ & & & \\
& PsA, prior biologic & 1.45 & $1.06-1.97$ & 0.018 \\
& $(n=264)$ & & & \\
Obesity $\left(B M I, k g / m^{2}\right)$ & $<30$ & ref & - & - \\
& $(n=1554)$ & & & \\
& $\geq 30$ & 1.15 & $1.02-1.31$ & 0.027 \\
& $(n=1620)$ & & & \\
\hline
\end{tabular}

$\mathrm{BMI}$, body mass index; $\mathrm{Cl}$, confidence interval; $\mathrm{HR}$, hazard ratio; $\mathrm{PsA}$, psoriatic arthritis; $\mathrm{PsO}$ psoriasis; ref, reference; UST, ustekinumab.

Disclosure of Interests: Alexis Ogdie Consultant of: AbbVie, Amgen, Bristol-Myers Squibb, Celgene, Corrona, Janssen, Eli Lilly, Novartis and Pfizer, Grant/ research support from: Pfizer to Penn, Novartis to Penn, Amgen to Forward/ NDB, William Tillett Speakers bureau: AbbVie, Amgen, Celgene, Eli Lilly, Janssen, Novartis, Pfizer and UCB, Consultant of: AbbVie, Amgen, Celgene, Eli Lilly, Janssen, Novartis, MSD, Pfizer and UCB, Grant/research support from: AbbVie, Celgene, Eli Lilly, Janssen and UCB, Alun Passey Employee of: Janssen-Cilag Ltd, Patricia Gorecki Employee of: Janssen-Cilag Ltd.

DOI: 10.1136/annrheumdis-2021-eular.1997

\section{POS1053 COMPARISON OF BASELINE CHARACTERISTICS BETWEEN PATIENTS CONTINUING OR DISCONTINUING APREMILAST AT TWELVE MONTHS IN THE REWARD STUDY (THE NETHERLANDS)}

R. Bos ${ }^{1}$, T. Jansen ${ }^{2}$, S. De Jong ${ }^{3}$, A. Castiglia ${ }^{4}$, M. Vis ${ }^{5} .{ }^{1}$ Medisch Centrum Leeuwarden, Rheumatology, Leeuwarden, Netherlands; ${ }^{2}$ Viecurie MC, Rheumatology, Venlo, Netherlands; ${ }^{3}$ Amgen BV, Medical Affairs, Breda, Netherlands; ${ }^{4}$ Amgen Europe $\mathrm{GmbH}$, Medical, Rotkreuzt, Switzerland; ${ }^{5}$ Erasmus MC, Rheumatology, Rotterdam, Netherlands

Background: Previous analysis of the REWARD study reported that patients with limited joint involvement have a considerable burden of disease ${ }^{1}$. Recent data suggest that patients with moderately active psoriatic arthritis ( $P s A)$ and a limited joint involvement have a high likelihood of achieving treatment goals when treated with apremilast ${ }^{2}$. According to EULAR recommendations a PDE4 inhibitor may be considered in patients with mild disease and an inadequate response to at least one csDMARD, in whom neither a bDMARD nor a JAK inhibitor is appropriate and the value of apremilast may be found in treating patients with relatively mild disease (oligoarticular) ${ }^{3}$.

Objectives: The objective of this prospective, multicentre, non-interventional study is to describe patient reported outcomes, effectiveness and real-life use of apremilast in patients with PsA. Patients will be followed up for a maximum of 12 months. This interim analysis compared the baseline characteristics and experience on apremilast for two subgroups of patients, those remaining on apremilast versus the ones that discontinued.

Methods: In this interim analysis we included patients with data available a cut-off date of 03 November 2020. Patient enrollment and follow up of current subjects is ongoing. Descriptive statistics (n's and percents for categorical data means for continuous data) were used to summarize the baseline data by subgroup. Kaplan Meier plots are presented to show patients' experience on apremilast by subgroup.

Results: 85 patients were included in the analysis. 30 patients have completed the study, 39 patients have discontinued and 16 are ongoing. At baseline 22 (26\%) patients were biologic experienced and 62 (74\%) were biologic naïve. Both groups had a comparable disease activity measured with clinical disease activity in psoriatic arthritis (cDAPSA) scores. Biologic experienced patients had a longer disease duration compared to biologic naïve patients (mean 9.7 vs 6.2 years) Inefficacy of previous medication was the main reason for starting apremilast in both subgroups. Overall, $86 \%(n=69)$ of patients were still receiving apremilast at month $3,60 \%(n=46)$ at month 6 , and $41 \%(n=26)$ at month 12 (Figure 1). Drug survival (length of time until discontinuation of apremilast) for biologic naïve patients was $93 \%$ at month 3,73\% at month 6 and $58 \%$ at month 12 . Drug survival of biologic experienced patients was $67 \%, 20 \%$, and $0 \%$ at months 3,6 , and 12, respectively. At baseline mean values of body mass index (BMI), swollen joint count (SJC), tender joint count (TJC), psoriatic arthritis impact of disease (PsAID) were comparable between both groups (Table 1). Reasons for discontinuation were mainly lack of efficacy (49\%) and adverse events $(44 \%)$. In this analysis the nature and frequency of adverse events is in line with the known profile of apremilast.

Conclusion: In this interim analysis, patients who were biologic naïve had a better probability to remain on treatment than those who were biologic experienced. Baseline characteristics were similar between the two groups, apart from disease duration that was longer in the biologic experienced group. Best drug survival is achieved when apremilast is prescribed earlier in the PsA treatment course, before biologics and after csDMARDs, as per apremilast EU label.

\section{REFERENCES:}

[1] Jansen TL, et al. Ann Rheum Dis. 2019;78:913 [abstract FRI0442]

[2] Mease PJ, et al. Arthritis Care Res 2020726 814-821

[3] Gossec L, et al. Ann Rheum Dis 2020;79:700-712

Disclosure of Interests: Reinhard Bos Consultant of: AbbVie BV, Genzyme Europe, Janssen-Cilag, Novartis, Pfizer, Grant/research support from: Galapagos, Tim Jansen Consultant of: AbbVie, Celgene Corporation - consultant Speakers bureau: Grunenthal, Sobi - speakers bureau, Grant/research support from: ReumaNederland, Olatec, Grunenthal - grant/research support, Sylvia de Jong Shareholder of: Employee of Amgen Inc, Employee of: Employee of Amgen Inc, Antonio Castiglia Shareholder of: Employee of Amgen Inc, Employee of Employee of Amgen Inc, Marijn Vis Consultant of: AbbVie, Celgene Corporation, Eli Lilly, Novartis, Pfizer, Grant/research support from: Novartis, Pfizer, AbbVie, Celgene Corporation, Eli Lilly, Novartis, Pfizer.

DOI: 10.1136/annrheumdis-2021-eular.208

\section{POS1054 UPADACITINIB PHARMACOKINETICS AND EXPOSURE-RESPONSE RELATIONSHIPS FOR EFFICACY AND SAFETY IN PSORIATIC ARTHRITIS - ANALYSES OF THE PHASE 3 SELECT-PSA STUDIES}

E. Muensterman ${ }^{1}$, B. Engelhardt ${ }^{1}$, S. Gopalakrishnan ${ }^{2}$, J. Anderson ${ }^{3}, \underline{M}$ E. Mohamed ${ }^{1}$. 'AbbVie, Clinical Pharmacology and Pharmacometrics, North Chicago, United States of America; ${ }^{2}$ Merck KGaA, Translational Medicine, Darmstadt, Germany; ${ }^{3}$ AbbVie, Clinical Development, North Chicago, United States of America

Background: Upadacitinib (UPA) is an oral, reversible, JAK inhibitor approved for the treatment of rheumatoid arthritis (RA). The efficacy and safety profile of UPA in psoriatic arthritis (PSA) has been established in the SELECT-PsA program which includes two global Phase 3 studies.

Objectives: These analyses characterize UPA pharmacokinetics and exposure-response relationships for efficacy and safety endpoints using data from the SELECT-PsA studies.

Methods: The SELECT-PsA program enrolled patients with prior inadequate response (IR) or intolerance to $\geq 1$ non-bDMARD1 $(\mathrm{N}=1705)$ and prior IR or intolerance to $\geq 1$ bDMARD2 ( $N=642$ ). Data from both trials was integrated for patients receiving placebo (PBO), UPA $15 \mathrm{mg}$ once daily (QD) and UPA $30 \mathrm{mg}$ $\mathrm{QD}$; adalimumab data was excluded from this analysis. UPA pharmacokinetics were characterized in PsA patients using Bayesian population pharmacokinetics analyses and utilizing prior information from analyses in healthy subjects and RA patients. Exposure-response analyses were conducted using logistic regression to characterize the relationships between upadacitinib average plasma concentration during a dosing interval (Cavg) and the percentage of patients achieving 